\title{
A Factor Analysis Study on the Mission Characteristics of Taiwanese Community Colleges
}

\author{
Wei-ni Wang \\ National Chung Cheng University, Taiwan
}

\begin{abstract}
There is a certain degree of assumption that a mission statement reveals the utmost vision of an organization in terms of what it seeks to become and who it wants to serve. To examine the general public's identification of the stated missions of the Taiwanese community colleges, a national survey was conducted to assess people's knowledge of institutional missions of these colleges. Four hundred twenty-one effective responses were received, and data were analyzed mainly by exploratory factor analytic methods.

Six factors, including "Human and Social Capital Enhancement," "Value and Action Construction," "Individual and Community," "Personal Learning and Growth," "Society and Culture," and "Public Participation and Action" were extracted, and these factors indicated that perspectives regarding missions of community colleges in Taiwan might greatly divergent. The Pearson Product-Moment correlation coefficient was used to investigate the relationships between missions identified and socio-demographic characteristics. The data showed that age, income, knowledge of community colleges, and enrollment experiences possessed significant degrees of association with the factors extracted. More research with different methods was encouraged to further study people's perception of the community college model in Taiwan in order to enhance its accountability.
\end{abstract}

\section{Introduction}

The mission of an organization or institution has been viewed as the purpose, strategy, values and behavioral standards of an organization [1]. It is often formulated and articulated in the form of a mission statement for immediately generating a shared sense of organizational meaning to organizational constituents and/or the public. In other words, mission statements are instruments invested in and created by organizations to communicate a positive image, by addressing specific issues, such as the purpose, values, goals, and strategies of the organization. There is also a certain degree of assumption that a mission statement reveals the utmost vision of an organization in terms of what it seeks to become and who it wants to serve [2].

The Taiwanese community college ${ }^{1}$ has a unique origin. Unlike many alike models that were created for the foremost purpose of increasing people's access to liberal and vocational education, the Taiwanese model was initiated after the revocation of martial law by NGO professionals with the mission aimed at liberalizing the dissemination of knowledge from elite institutions and to advance the formation of a civil society. Since 1998, a total of 85 community colleges have been established to date [3]. However, does the general public indeed relate themselves to the organizational mission of the Taiwanese community college model? Is the general public able to capture what the community colleges in Taiwan intending to serve as stated in their mission statements?

The paper reports on an empirical study designed to assess people's understanding of institutional missions of community colleges in Taiwan. The primary purpose was to employ factor analytic methods to examine the general public's knowledge of the stated missions of the Taiwanese community colleges. Then, the relationships between missions identified and socio-demographic characteristics were investigated. The paper concludes with a discussion of findings and analytical limitations.

\footnotetext{
1 Community colleges in Taiwan are called community "universities" in its language. In order to facilitate discussion, minimize rhetorical confusion, and parallel to their international counterparts, "community college" is hereby used in this article to refer to the Taiwanese "community universities."
} 


\section{Literature review}

Two sections of literature were reviewed to obtain a general understanding of the topic. One was a brief overview of the Taiwanese model of community colleges, and another was an analysis of current empirical studies on the missions of these unique institutions.

\subsection{Overview of Taiwanese Community Colleges and Missions Thereof}

Taiwan was a single-party country under strict martial law until 1987. After martial law was revoked, the country moved to a multiparty democracy with many political and social changes, some initiated by groups outside the sphere of the state [4], including reforms of higher education. In 1994, Dr. Wu-shiung Huang initiated the advocacy of establishing community colleges [5] in order to respond to the global trend of growing emphasis on adult and community education. According to Huang's profound blueprint [6], community colleges in Taiwan would take on the role of aiming to liberalize the dissemination of knowledge and advance the formation of the civil society by offering various educational programs. Huang's ideas were well received, and a follow-up group of supporters from various non-governmental institutions began a grassroots movement in establishing community colleges as a means to foster diverse learning needs in order to build a civil society. Since the founding of the first community colleges in the September of 1998, the numbers have been increasing rapidly, and there are currently 85 community colleges to date [3]. The rapid growth of Taiwanese community college education is very promising, and it also indicates that such educational ideals have been wellaccepted by the general public [7].

The development of these colleges is tightly tied to the social contexts in Taiwan. Affected by the national college entrance examination for decades, first, Taiwanese people's access to postsecondary education is relatively selective, compared to many countries, such as the United States. Second, knowledge and subject matters that are not required for the college entrance exam are likely to be neglected by students, parents, schools, and even the society. Therefore, the Taiwanese society has become one that overly emphasizes credentials, textbook knowledge, and individual success. Recognizing the challenges from the global trends of adult and community education and lifelong learning, the establishment of community colleges is the intervention expected to provide access to postsecondary education for those who would never have had the opportunity and to engage people in multidimensional learning. To be more specific, and initially proposed by Dr. Wu-shiung Huang, the mission of community colleges in Taiwan is made up of several components: to improve community development and quality of life, to reduce credentialism, and to build a civil society by means of providing adults access to modern knowledge and postsecondary education, emphasizing learnercentered instruction, and encouraging social and community engagement [6].

2.1.1 Curriculum. Generally speaking, the community colleges in Taiwan offer three kinds of programs: academic programs, avocational programs, and community education and involvement programs [5]. Academic programs are basically general education in the areas of liberal arts, social sciences, and natural sciences. Avocational programs provide a large array of classes to enrich personal interests and life skills. The last but not the least, community education and involvement programs (normally operated in the form of clubs) lead learners to become actively involved in community affairs and provide them opportunities to develop citizenship. A certificate will be granted after the completion of each class; learners who finish 128 credits are expected to receive an associate's degree conferred by the enrolled community colleges and local governments.

2.1.2. Operation and governance. Similar to many pioneering community colleges in the United States, most of community colleges in Taiwan reside in the campuses of local public elementary and secondary schools. Such a collaborative relationship between local governments and community colleges rigorously link public resources and this particular new educational initiation together, based on a functional concern with good use of resources and expertise from both ends. As a result, Taiwanese community colleges have been positioned as privatemanagement-of-public-establishment educational institutions, founded by community groups or private organizations that operate under a written contract with the governments, on which detailing with the institutional mission and visions, administration, and performance evaluation [5][6]. Currently, only a few colleges are directly administrated by local governments.

\subsection{Empirical Studies on Taiwanese Community College Missions}

Both practitioners and researchers seem to accept the mission introduced above with no hesitation. For 
example, Hsiao [8] condensed the mission framework to three categories: knowledge emancipation, social reform, and value reconstruction. Hsu [9] added two components onto Hsiao's model, self actualization and establishment of a civil society. Obviously, Huang's concept by and large dominates the discourse of community college missions and rhetorical modifications are frequently found in literature without critical reflections.

Empirically, works of Ho and Chao [10], Lin [11], and Wang, Hsieh, and Chan [12] were the few studies that directly dealt with Taiwanese community college missions. The first two studies were approached similarly to explore to what degree community college students could identify missions of the colleges through their learning experiences; somewhat expectably, these researchers adopted Huang's concept as a frame of reference. Furthermore, research subjects of these two studies were students attending the community colleges, indicating the assumption that they would have been more aware of the organizational missions than the general public since they were the insiders. The findings were hence hardly reliable if hoping to generalize them to portray the general public's identification and knowledge of community college missions in Taiwan.

Rather than solely using Huang's conceptualization as a frame of reference, Wang, Hsieh and Chan [12] took another approach to study community college missions. They argued that the missions might have evolved differently after a decade of practice since 1998, although Huang's model was fundamental and still influential. A content analysis on the mission statements of the Taiwanese community colleges was conducted, and the researchers found new themes emerged from the mission statements analyzed while those initially proposed by pioneering community college advocates were largely retained.

Literature on mission statements prevalently discusses their role in facilitating direction establishment and formation [2][13], in aiding organizational strategy implementation [1], and in affecting organizational performance [14]. Another body examines the components of a mission statement (for example, Hill and Jones [15], and Piercy and Morgan [16]). The three Taiwanese studies cited above did not provide direct answers to these dimensions, yet they added detailed information of the purposes, goals, values and strategies embedded in the Taiwanese community college model. More extended research into how these mission statements have led to the operation of such organizations would be needed in further understanding the understudied adult education model.

\section{Methodology}

This section describes the sampling and data analysis methods used to empirically investigate people's knowledge of missions of community colleges in Taiwan. A survey method was employed to conduct this study. In this section, sampling procedures, instrument, and accompanying data analysis methods are to be explained.

\subsection{Sampling and data collection procedures}

Data for the study were drawn from a national survey. Since the community college model is relatively young, we assumed that people living in the townships where community colleges were located would be more familiar with the concept and services associated with such organizations. Therefore, a modified cluster sampling technique was employed to select research subjects: thirteen townships, representing various organizational characteristics such as location and mode of managements, were chosen; survey questionnaires were mailed to registered community development agencies residing in the chosen townships for distributing questionnaires to community residents. Numbers of questionnaires sent to each agency were calculated proportionally based on the composition of total community colleges in Taiwan. A total of 1959 questionnaires were sent during the initial mailing.

Data collection lasted for approximately two months, including one telephonic reminder to agency representatives that followed two weeks after the initial mailing. Two weeks after the phone to agencies, a postcard reminder was sent to the townships with a low number of responses, and a thank you note was mailed to all agencies as the last reminder six weeks after the initial mailing.

The above procedures led to 446 respondents; the response rate of $22.77 \%$ is somewhat higher than the rate of around $20 \%$ usually reported for mailed surveys to large groups of community residents. Effective responses of 421 were finalized after a data clean-up and screening. The number also met the ratio requirement for a factor analytic study, namely that there should be at least five times as many respondents as instrument items [17].

\subsection{Instrument}

The research instrument of this study was a 54item questionnaire, which was developed primarily 
Table 1. Mission characteristics and respective variables

\begin{tabular}{|l|r|}
\hline \multicolumn{1}{|c|}{ Characteristics } & Components \\
\hline Increasing participation in public affairs & Component 1 \\
\hline Improving critical thinking and reflection & Component 2 \\
\hline Increasing student involvement & Component 3 \\
\hline Utilizing problem-based teaching methods & Component 5 \\
\hline Encouraging new ways of expression and appreciation of life & Component 6: \\
\hline Vitalizing community resources & Component 7 \\
\hline Vitalizing school resources & Component 8 \\
\hline Liberalizing knowledge creation and dissemination & Component 9 \\
\hline Nurturing lifelong learning & Component 10 \\
\hline Education for all & Component 11 \\
\hline Passing down cultural legacy & Component 12 \\
\hline Developing local human resources and capital & Component 13: Providing \\
\hline Solving societal problems & programs for specific \\
\hline Aboriginals & populations \\
\hline Women & Component 14 \\
\hline Farmers & Component 15 \\
\hline People with disabilities & Component 16 \\
\hline Promoting beliefs of particular religions & Component 17 \\
\hline Localizing knowledge & Component 18 \\
\hline Fostering identification of personal values and worldview &
\end{tabular}

based on the findings of a previous study on community college missions [12]. The 2008 study identified 21 mission characteristics based on a content analysis of mission statements of Taiwanese community colleges, which were then adapted in this study at hand to further assess people's understanding thereof. The 21 characteristics were regrouped into 18 components (see Table 1) for generating better and sizeable conceptualization of different missions.

As a result, the main body of the questionnaire contained 54 items representing 18 mission characteristics (components). Specifically, the survey instrument was composed of a number of sociodemographic questions, a series of 36 items regarding the respondents' personal interests (given the assumption that people tend to pay extra attention to things which interest them), and a list of 18 items of respondents' opinions of their ideal perception of community colleges in Taiwan. The scaling technique used for the non-demographic questions involved a Likert response format of four descriptors: always, sometimes, seldom, and never for personal interest items; and strongly agree, somewhat agree, disagree, and strongly disagree for perception items. In addition, expert validity and pretesting procedures [17] were administered beforehand to improve the quality of the formal instrument; thus reliability and validity of the study were warranted.

\subsection{Data analysis}

Data were analyzed by four statistical methods. First, descriptive statistics were applied to understand the composition of the sample, as well as distribution and frequencies of responses to sociodemographic questions. Second, a brief comparison of this study at hand to the results of the previous content analysis [12] was conducted. Third, a principal components exploratory factor analysis was employed as a data dimensionality reduction approach to define the general public's knowledge of Taiwanese community college missions. Last, the Pearson Product-Moment correlation coefficient was used to investigate the relationships between missions identified and socio-demographic characteristics of community residents.

\section{Results and discussion}

The data collection procedure yielded 446 questionnaire responses in this study. This section describes the results of the data analyses.

\subsection{Descriptive statistics of the sample}

After a data clean-up for missing values and incomplete responses, a total of 421 effective responses were recorded; $46.1 \%$ of the respondents 
Table 2. Descriptive statistics and comparison with content analysis results

\begin{tabular}{|l|c|c|c|c|c|c|}
\hline \multirow{2}{*}{\multicolumn{1}{|c|}{ Mission Characteristics }} & \multicolumn{2}{c|}{$\begin{array}{c}\text { Content } \\
\text { Analysis }\end{array}$} & \multicolumn{2}{c|}{$\begin{array}{c}\text { Personal } \\
\text { Interests }\end{array}$} & \multicolumn{2}{c|}{$\begin{array}{c}\text { Ideal } \\
\text { Mission }\end{array}$} \\
\cline { 2 - 6 } & frequency & rank & mean & rank & mean & rank \\
\hline Nurturing lifelong learning & 48 & 1 & 3.271 & 2 & 2.960 & 15 \\
\hline Increasing participation in public affairs & 44 & 2 & 3.024 & 7 & 3.145 & 9 \\
\hline Vitalizing local resources & 42 & 3 & 2.840 & 12 & 2.900 & 16 \\
\hline Fostering identification of personal values and worldview & 38 & 4 & 2.915 & 11 & 2.827 & 18 \\
\hline Developing local human resources and capital & 30 & 5 & 3.122 & 5 & 2.829 & 17 \\
\hline Sustaining community development & 28 & 6 & 2.964 & 10 & 3.349 & 1 \\
\hline Localizing knowledge & 17 & 7 & 2.815 & 14 & 3.208 & 7 \\
\hline Passing down cultural legacy & 16 & 8 & 2.825 & 13 & 3.311 & 2 \\
\hline Uniting social reform efforts & 13 & 9 & 2.728 & 16 & 3.307 & 3 \\
\hline Liberalizing knowledge creation and dissemination & 13 & 9 & 3.113 & 6 & 3.264 & 4 \\
\hline Improving critical thinking and reflection & 12 & 11 & 2.966 & 9 & 3.003 & 13 \\
\hline Education for all & 12 & 11 & 3.167 & 4 & 3.003 & 14 \\
\hline Solving societal problems & 10 & 13 & 3.289 & 1 & 3.240 & 5 \\
\hline Providing programs for specific populations & 7 & 14 & 2.535 & 18 & 3.164 & 8 \\
\hline Utilizing problem-based teaching methods & 6 & 15 & 3.246 & 3 & 3.229 & 6 \\
\hline Encouraging new ways of expression & 5 & 16 & 2.984 & 8 & 3.105 & 11 \\
\hline Increasing student involvement & 4 & 17 & 2.718 & 17 & 3.139 & 10 \\
\hline Promoting beliefs of particular religions & 4 & 17 & 2.798 & 15 & 3.075 & 12 \\
\hline
\end{tabular}

lived in the north region of Taiwan, 33.5\% from the central region, $15.9 \%$ from the south, and $4.5 \%$ from the east. The regional composition of the respondents is similar to that of where community colleges in Taiwan reside: $50 \%$ in the north, $27.1 \%, 15.7 \%$, and $5.7 \%$ from the central, south and east, respectively [12]. The results warranted the representation of the sample of the study.

In the sample, women outnumbered men; the majority (52.6\%) of participants were between the ages of 46 to 65 . Almost 80 percept had earned high school diplomas or higher, with more than $35 \%$ of all respondents having obtained college and graduate school degrees. The most common religious affiliation in the sample was Taoism. In terms of the respondents' knowledge of the community college missions in Taiwan, 95\% of the participants mentioned they had heard of the model, but more than half of them confessed their little knowledge of the details of their organizational missions. Only one out of five people in the sample had taken courses at the community colleges.

\subsection{Comparison with results of content analysis on mission characteristics}

Questions like "I participate in ABC" and "I am interested in ABC" were included in the questionnaire of this research to understand respondents' personal interests, with $\mathrm{ABC}$ referring to activities associated with mission characteristics.
The higher one scored, the greater level of involvement was declared, which indicated that the representing mission was more frequently practiced and identified in one's life. The data showed that activities containing the essences similar to the mission characteristics of "solving societal problems," "nurturing lifelong learning," and "utilizing problem-based teaching methods" were rated the highest by the respondents. The three activities that the respondents were least interested in included, "uniting social reform efforts," "increasing student involvement," and "providing programs for specific populations."

Additionally, the respondents were asked to answer questions like, "I think the ideal community college is able to..." in order to directly assess people's knowledge and perception of why community colleges in Taiwan existed and what they should serve. The top three mission characteristics identified were "sustaining community development," "passing down cultural legacy," and "uniting social reform efforts," while "vitalizing local resources," "developing local human resources and capital," and "fostering identification of personal values and worldview" were rated the lowest.

If comparing with the results from the content analysis study (see Table 2), great differences were found based on the descriptive statistic analysis. Although the community colleges frequently stated "nurturing lifelong learning," "increasing participation in public affairs," and "vitalizing local 
resources" in their mission statements, the same

investigate the differences and association between

Table 3. Factor analysis on respondents' personal interests relating to missions

\begin{tabular}{|l|c|c|}
\hline \multicolumn{1}{|c|}{ Personal interest items (component) } & \multicolumn{2}{|c|}{ Factor } \\
\cline { 2 - 3 } & $\mathbf{1}$ & $\mathbf{2}$ \\
\hline (4) Utilizing problem-based teaching methods & .937 & -.108 \\
\hline (7) Liberalizing knowledge creation and dissemination & .926 & .111 \\
\hline (16) Fostering identification of personal values & .765 & .111 \\
\hline (2) Improving critical thinking and reflection & .753 & .124 \\
\hline (8) Nurturing lifelong learning & .748 & .064 \\
\hline (12) Solving societal problems & .708 & .029 \\
\hline (5) Encouraging new ways of expression & .687 & .326 \\
\hline (11) Developing local human resources and capital & .628 & .361 \\
\hline (9) Education for all & .538 & .797 \\
\hline (1) Increasing participation in public affairs & .019 & .707 \\
\hline (14) Promoting beliefs of particular religions & -.233 & .696 \\
\hline (17) Sustaining community development & .268 & .676 \\
\hline (3) Increasing student involvement & .221 & .671 \\
\hline (18) Uniting social reform efforts & .252 & .587 \\
\hline (10) Passing down cultural legacy & .224 & .520 \\
\hline (6) Vitalizing local resources & .348 & .495 \\
\hline (15) Localizing knowledge & .423 & Public Participation and \\
\hline (13) Providing programs for specific populations & .361 & Action \\
\hline Factor & Personal Learning \& & 1.370 \\
\hline Eigenvalue & Growth & .935 \\
\hline \% of variance explained & 10.771 & 7.611 \\
\hline Cronbach's Alpha & 59.838 & .936 \\
\hline KMO=0.954, Bartlett test, p=0.000, Cumulative \% of loading, 67.45\%, Component Correlation, 0.602 \\
\hline
\end{tabular}

degree of emphasis was not reflected in the the three sets of findings, as well as their respondents' answers to the types of activities they were interested in and to their opinions on what an ideal community college ought to be. Of note, the top four picks of ideal community college missions, which were "sustaining community development," "passing down cultural legacy," "uniting social reform efforts," and "liberalizing knowledge creation and dissemination," were only ranked 6 9 based on mission counts, while respondents' bottom three picks were the top three most frequently appeared mission characteristics in the 2008 study [12].

The results indicated that how community college administrators positioned themselves through mission statements might not be the same as what the general public thought they were. The differences found in this study were also alerting to community college administrators as they might not have transmitted their organizational missions precisely to their constituents. On the other hand, missions perceived by the respondents as ideal to the community college setting did not receive compatible levels of attention on the written mission statements, also indicating a perception gap between community college practitioners and the general public. Further studies adopting appropriate statistical methods will be recommended to further

\subsection{Factor analysis}

The primary purpose of factor analysis method is to define the underlying structure among the variables in the analysis [17]. Accordingly, the method is appropriate to investigate the general public's identifications of the stated missions of the Taiwanese community colleges. Specifically, a principal component exploratory factor analytic method with an Oblique rotation was conducted to generate the factors underlying the 18 community college mission components, expecting to understand what factors embedded among the mission components would be contributed to the general public's perceived mission of the Taiwanese community colleges. All analyses run by this method followed the rules of thumb [2][17]: components with eigenvalues greater than 1.0; the results of the Bartlett test of sphericity were statistically significant, suggesting the data were appropriate for factor analysis; the Kaiser-Meyer-Olkin (KMO) Measure of Sampling Adequacy had a value of 0.70 and above to be considered good; the instrument 
contained at least 10 observations per variable; components with a factor loading under the value of 0.45 , or cross-loaded, were deleted; and Cronbach's Alpha of each factor was above the minimum value of 0.5 as an indication of reliability.

The first factor analysis was done to classify types of activities that were of interest to the respondents. Two factors emerged from the principal components analysis of the 18 activities (A.K.A. the 18 components in Table 1) composed of mission characteristics of community colleges in Taiwan. Table 3 shows the content of the rotated factors, as well as the percentage of the total variance explained by each. As indicated in the table, the two-factor solution accounted for about 67 percent of the total variance among the 18 components. The first factor was labeled "Personal Learning and Growth," because the included mission components placed greater emphasis on learning new skills and striving for more educational opportunities. The component, "developing local human resources and capital," might not be viewed as individualistic as the others, but since its essence was to increase the competitiveness of community residents, we argued it was fair to regard it as one with an orientation towards personal learning.

The second factor was labeled, "Public Participation and Action," because clearly, these items revealed a strong sense of action. Although the 18 components were evenly distributed between the two factors, the "Personal Learning and Growth" factor shared a higher loading. The results suggested that people in Taiwan showed some resistance to proactive activities and preferred to be involved in liberal arts and personal enrichment activities. Furthermore, it is discouraging in the sense that the vision of building a civil society through people's active participation in public work, advocated by the pioneers in the 1990s, has not been widely shared by the general public. Much must yet be accomplished to achieve the goal.

Table 4. Factor analysis on perceived missions of ideal community colleges

\begin{tabular}{|c|c|c|}
\hline \multirow{2}{*}{ Perceived Ideal Mission Items } & \multicolumn{2}{|c|}{ Factor } \\
\hline & 1 & 2 \\
\hline (14) Promoting beliefs of particular religions & .784 & .281 \\
\hline (5) Encouraging new ways of expression & .696 & -.065 \\
\hline (1) Increasing participation in public affairs & .690 & -.078 \\
\hline (12) Solving societal problems & .658 & .000 \\
\hline (18) Uniting social reform efforts & .649 & -.158 \\
\hline (10) Passing down cultural legacy & .608 & -.145 \\
\hline (17) Sustaining community development & .574 & -.250 \\
\hline (2) Improving critical thinking and reflection & .522 & -.412 \\
\hline (15) Localizing knowledge & .510 & -.313 \\
\hline (7) Liberalizing knowledge creation and dissemination & .510 & -356 \\
\hline (9) Education for all & -.101 & -.877 \\
\hline (6) Vitalizing local resources & .037 & -.802 \\
\hline (3) Increasing student involvement & .016 & -.794 \\
\hline (13) Providing programs for specific populations & .066 & -.681 \\
\hline (16) Fostering identification of personal values & .279 & -.518 \\
\hline (11) Developing local human resources and capital & 395 & -.501 \\
\hline (4) Utilizing problem-based teaching methods & .424 & -.485 \\
\hline Factor & $\begin{array}{l}\text { Value and Action } \\
\text { Construction }\end{array}$ & $\begin{array}{l}\text { Human and Social } \\
\text { Capital Enhancement }\end{array}$ \\
\hline Eigenvalue & 8.435 & 1.235 \\
\hline$\%$ of variance explained & 49.615 & 7.263 \\
\hline Cronbach's Alpha & 0.89 & .0 .89 \\
\hline \multicolumn{3}{|c|}{$\begin{array}{c}\mathrm{KMO}=0.945 \text {, Bartlett test, } \mathrm{p}=0.000 \text {, Cumulative } \% \text { of loading, } 56.878 \\
\text { Component Correlation, }-0.555\end{array}$} \\
\hline
\end{tabular}

Another factor analysis was administrated to investigate how the public perceived the missions of ideal Taiwanese community colleges. The same procedures were taken, and it effectively removed "nurturing lifelong learning” (Component 8) because the loading values were too low to fit into each factor initially generated. The data were processed again without Component 8 and two factors were yielded.
Table 4 lists the findings: the two-factor solution accounted for approximately $57 \%$ of the total variance among the 17 components of mission characteristics; the content of the rotated factors as well as the percentage of the total variance explained by each were also include in the table.

The first factor was called "Value and Action Construction" because these grouped components 
highlighted either the outcome or the process of constructing new values and actions. In other words, respondents acknowledged that community colleges in Taiwan ought to play the facilitative role in guiding their clientele and constituents to generate new ways of being and thinking in which values and actions would be reflected upon and constructed for the betterment of the society or the individuals. Named "Human and Social Capital Enhancement," the second factor was comprised of 7 components that emphasized the missions striving to advance individual and collective skills and capacities. However, no immediate explanation is at hand for the strong loading of Component 16 (definition of which was to assist learners to re-learn their life experiences and discover the worldview that are meaningful to themselves [12]), since this mission component was relatively similar to the characteristics of "Value and Action Construction" factor.

The authors of this paper argued that what people are interested in may lead to their expectation from an organization of which they are or with which they can be potentially associated with; similarly, members of an organization may cultivate new interests that are in lines with organizational missions and characteristics. Such an argument was influenced by literature on organizational identification [18][19] with the concept being defined as feelings of solidarity with the organization; attitudinal and behavioral support for the organization; and perception of shared characteristics with other organizational members. Since everyone is potentially a member (learner, student) of community colleges in Taiwan, the concept of organizational identification was used in this study to investigate to what degree the mission characteristics of community colleges would be indentified through the activities people were involved in and the opinions they had of these organizations.

Therefore, we integrated all questions and ran a correlation test, obtaining Pearson correlation value of personal interest items and ideal mission items of $0.353, \mathrm{p}<.001$, and so another factor analysis was conducted. Table 5 shows the content of the Oblique rotated factors, as well as the percentage of the total variance explained by each. After deleting two crossloaded components, the two-factor solution accounted for about 70 percent of the total variance among the 16 components. The first factor was labeled "Individual and Community," and the other was named, "Society and Culture," due to the distinction between contexts of which the missions could be most likely applied to and/or influential on.
All 6 factors extracted from the analysis, "Human and Social Capital Enhancement" factor received the highest score $(\mathrm{M}=3.47, \mathrm{SD}=0.47)$ and "Public Participation and Action" the lowest $(\mathrm{M}=2.79$, $\mathrm{SD}=0.67)$, the remainders were "Value and Action Construction” ( $\mathrm{M}=3.33, \mathrm{SD}=0.46)$, "Individual and Community" ( $\mathrm{M}=3.18, \mathrm{SD}=0.50)$, "Personal learning and Growth" (M=3.11, SD=0.56), and "Society and Culture" $(M=2.99, S D=0.57)$. Based on the means and standard deviations, it was apparent that the utmost missions that Taiwanese community colleges intended to achieve - factors named "Society and Culture" and "Public Participation and Action" received the least recognition and identification. In other words, people in Taiwan tend to be in favor of activities that are egoistic rather than altruistic. Reflecting upon observations from practice, the finding was not surprising since many more people enrolled in personal enrichment classes and fewer people devoted their time to club courses that were geared in a sense towards service learning. How to draw people's attention to issues and activities of greater social consciousness is important to fulfill intended community college missions. Analysis of variances could be conducted in the future to further investigate the differences between the factors and the mission components.

\subsection{Pearson Correlation Coefficient}

Measures of Pearson Product-Moment correlation coefficient were applied to identify the relationships between the findings from the three sets of factor analyses and other variables. The correlations among the socio-demographic variables and factors of the study are presented in Table 6 . The data show that age, income, knowledge of community colleges, and enrollment experiences were the four sociodemographic variables possessing significant degrees of association with the factors extracted; region, gender, educational level, and religion did not statistically affect people's understanding and perceptions of the Taiwanese community college model. Of note, the negative correlation coefficient values of Knowledge and Enrollment raised questions, and using different statistical methods, such as logistic regressions, might better detect the relationships. Interestingly, people's perceived ideal missions seemed to be formed regardless of any demographic reasons; it may be because people expected everything from the community colleges, or the concept of community college missions has been perceived so differently by the general public that no pattern could be formed. Further investigation would be valuable to understand the details. 
Table 5. Factor analysis on identification of community college missions

\begin{tabular}{|c|c|c|}
\hline \multirow{2}{*}{ All Items Combined } & \multicolumn{2}{|c|}{ Factor } \\
\hline & 1 & 2 \\
\hline (7) Liberalizing knowledge creation and dissemination & .963 & -.191 \\
\hline (4) Utilizing problem-based teaching methods & .944 & -.152 \\
\hline (8) Nurturing lifelong learning & .890 & -.045 \\
\hline (16) Fostering identification of personal values & .874 & .002 \\
\hline (2) Improving critical thinking and reflection & .850 & .002 \\
\hline (11) Developing local human resources and capital & .841 & 092 \\
\hline (9) Education for all & .809 & .076 \\
\hline (5) Encouraging new ways of expression & .786 & -.031 \\
\hline (12) Solving societal problems & .741 & -.012 \\
\hline (6) Vitalizing local resources & .662 & .300 \\
\hline (15) Localizing knowledge & .644 & 337 \\
\hline (17) Sustaining community development & .623 & 389 \\
\hline (13) Providing programs for specific populations & .559 & 319 \\
\hline (14) Promoting beliefs of particular religions & -.085 & .875 \\
\hline (1) Increasing participation in public affairs & .367 & .585 \\
\hline (10) Passing down cultural legacy & 451 & .554 \\
\hline Factor & $\begin{array}{l}\text { Individual and } \\
\text { Community }\end{array}$ & Society and Culture \\
\hline Eigenvalue & 10.326 & 1.127 \\
\hline$\%$ of variance explained & 64.536 & 7.047 \\
\hline Cronbach's Alpha & .96 & .77 \\
\hline $\begin{array}{r}\mathrm{KMO}=0.958, \text { Bartlett test, } \mathrm{p}=0.000 \text {, } \\
\text { Component Cor }\end{array}$ & $\begin{array}{l}\text { lative } \% \text { of loadi } \\
\text { n, } 0.507\end{array}$ & \\
\hline
\end{tabular}

Table 6. Correlations between the variables and factors

\begin{tabular}{|c|c|c|c|c|c|c|c|c|}
\hline Dimension and Factor & Region & Gender & Age & $\begin{array}{l}\text { Edu. } \\
\text { Level }\end{array}$ & Income & $\begin{array}{l}\text { Reli- } \\
\text { gon }\end{array}$ & $\begin{array}{l}\text { Know- } \\
\text { ledge }\end{array}$ & $\begin{array}{l}\text { Enroll- } \\
\text { ment }\end{array}$ \\
\hline Personal Interests & -.021 & -.097 & $325^{\star \star *}$ & .137 & $210^{* *}$ & .023 & $-.252^{* *}$ & $-.185^{\star \star}$ \\
\hline Perceived Ideal Missions & .028 & .002 & $108^{*}$ & .062 & .001 & -.084 & -.038 & -.042 \\
\hline Identification of the Missions & -.013 & -.080 & $342^{* *}$ & $159^{\star}$ & $198^{* \star}$ & -.003 & $-.249^{* *}$ & $-.185^{\star \star}$ \\
\hline Personal Learning and Growth & .004 & -.052 & $219^{\star \star *}$ & .128 & $196^{\star \star}$ & .034 & $-.258^{\star \star}$ & $-.180^{\star \star *}$ \\
\hline Public Participation and Action & -.056 & -.096 & $360^{* *}$ & .124 & $161^{\star * *}$ & -.014 & $-.208^{* *}$ & $-.138^{\star \star *}$ \\
\hline Value and Action Construction & -.028 & -.015 & $.145^{\star *}$ & .088 & .063 & -.069 & -.079 & $-.100^{*}$ \\
\hline $\begin{array}{l}\text { Human and Social Capital } \\
\text { Enhancement }\end{array}$ & -.023 & -.017 & .067 & .102 & .081 & -.079 & $-.108^{*}$ & -.065 \\
\hline Individual and Community & -.009 & -.051 & $245^{\star \star}$ & .131 & $186^{\star \star *}$ & .007 & $-.246^{* \star}$ & $-.168^{\star \star}$ \\
\hline Society and Culture & -.060 & -.084 & $397^{\star \star}$ & .123 & .086 & $-.125^{\star}$ & $-.116^{*}$ & $-.162^{\star \star}$ \\
\hline
\end{tabular}

\section{Conclusion}

There is a certain degree of assumption that a mission statement reveals the utmost vision of an organization in terms of what it seeks to become and who it wants to serve. To examine the general public's identification of the stated missions of the Taiwanese community colleges, a national survey was conducted to assess people's knowledge of institutional missions of these colleges. Four hundred twenty one effective responses were received, and data were analyzed mainly by exploratory factor analytic methods.

Six factors were extracted to analyze people's identification of community college missions from different angles, and the factor analyses results indicated that perspectives on missions of community colleges in Taiwan might be greatly 
divergent, yet altruistic types of missions were scored lower, suggesting people see community colleges as a place primarily providing services to increase personal enrichment and skills. The Pearson Product-Moment correlation coefficient was used to investigate the relationships between missions identified and socio-demographic characteristics. The data showed that age, income, knowledge of community colleges, and enrollment experiences possessed significant degrees of association with the factors extracted. Further studies adopting appropriate statistical methods are recommended to investigate the differences and association between the three sets of findings. Analysis of variances or logistic regression could be conducted in the future to further investigate the differences between the factors and the mission components of which.

This study provides preliminary empirical support for implications for marketing. Among the respondents, 95\% have heard of community colleges but slightly less than a quarter of people have taken classes; therefore, community college practitioners in Taiwan must compose more effective recruitment strategies to increase participation rate. Although people seem to realize the fundamental missions of the community colleges are to increase public participation, they show a lower degree of interest in relevant activities; how to foster community residents to develop such interests is imperative to fulfill the organizational missions.

Concluding, it would be fair to say that the growth in numbers of community colleges in Taiwan does indicate that the stated missions of such organizations are by and large well received, yet the degree of people's participation is needed to be enhanced. With further analysis, it is hopeful that this set of data would provide community college practitioners in Taiwan helpful information for organizing targeted marketing campaigns.

\section{Acknowledgements}

The author thanks the National Science Council of Taiwan (NSC96-2413-H-194-027 and NSC97-2410$\mathrm{H}$-194-076) for the financial support of this research. The author would also like to thank her graduate students, Hwei-jen Chan, Ong-fen Hsieh, Cheng-yi Cheng, and Chen-chi Kao, for their assistance in data collection and analyses.

\section{References}

[1] A. Campbell, and S. Yeung, "Creating a Sense of Mission”, Long Range Planning, 1991, pp. 10-20.
[2] J. Sidhu, "Mission Statements: Is It Time to Shelve Them?” European Management Journal, 2003, pp. 439446.

[3] National Association for the Promotion of Community University, Total Number of Community Universities, retrieved from http://www.napcu.org.tw/website/ (Access date: May 26, 2011).

[4] T. Wright, "Student Mobilization in Taiwan: Civil Society and Its Discontents", Asian Survey, 1999, pp. 9861008.

[5] Taipei City Government, Taipei Community Universities Report, Taipei City Government Press, Taipei, Taiwan, 1999.

[6] W. Huang, The Reconstruction of Taiwanese Education (2nd ed.), Yuen- liu, Taipei, Taiwan, 1997.

[7] C. Gu, "Three Directions of Deepening the Development of Community Universities”, retrieved from http://apcu.taconet.com.tw/html/report/special/special12a.h tm (Access date: October 5, 2001).

[8] C. Hsiao, "From the Points of View of Civil Society to Discuss the Development of Community University", Formosan Education and Society, 2004, pp. 1-25.

[9] Y. Hsu, "The Difficulty and Prospect for the Legalized System of Community University”, Educational Review, 2005, pp. 89-113.

[10] C. Ho, and S. Chao, “The Public's Identification with the Rationales and the Features of Community Universities: Insights from a Survey”, Taiwan Journal of Sociology of Education, 2001, pp. 1-38.

[11] S. Lin, The Study on the Ideas/Ideal of Community University of Nantou and the Identity of Its Students. Unpublished Master's Thesis, Puli, Nantou, Taiwan, National Chi Nan University, 2005.

[12] W. Wang, O. Hsieh, and H. Chan, "A Content Analysis of Mission Statements of Taiwanese Community Colleges" in Proceedings of 2008 American Association of Adult and Continuing Education International Preconference, Denver, Colorado, USA, pp. 215-229.

[13] S. Desmidt, A. Prinzie, and A. Heene, "The Level and Determinants of Mission Statement Use: A Questionnaire Survey”, International Journal of Nursing Studies, 2008, pp. 1433-1441.

[14] C. Bart, "Industrial Firms and the Power of Mission”, Industrial Marketing Management, 1997, pp. 371-383.

[15] C.W.L. Hill, and G.R. Jones, Strategic Management: An Integrated Approach. Houghton Mifflin, Boston, USA, 1997. 
[16] N.F. Piercy, and N.A. Morgan, "Mission Analysis: An Operational Approach", Journal of General Management, 1994, pp. 1-19.

[17] H. Chu, Qualitative Research and Statistic Methods, Wu-nan, Taipei, Taiwan, 2006.

[18] T.B. Cornwell, and L.V. Coote, “Corporate Sponsorship of a Cause: The Role of Identification in Perchance Intent”, Journal of Business Research, 2003, pp. 268-276.

[19] M. Patchen, Participation, Achievement, and Involvement on the Job, Prentice-Hall, New Jersey, USA, 1970. 